\title{
Pyrolysis of polymer waste is a source of motor fuels
}

Ksenya Hrynyshyn ${ }^{1}$, Volodymyr Skorokhoda ${ }^{2}$, Taras Chervinskyy ${ }^{3}$

1. Department of Chemical Technology of Plastics Processing, Lviv Polytechnic National University, UKRAINE,

Lviv, 12 Bandera street, E-mail: kseniia.o.hrynyshyn@lpnu.ua

2. Department of Chemical Technology of Plastics Processing, Lviv Polytechnic National University, UKRAINE, Lviv, 12 Bandera street, E-mail: volodymyr.yo.skorokhoda@lpnu.ua

3. Department of Chemical Technology of Oil and Gas Processing, Lviv Polytechnic National University, UKRAINE, Lviv, 12 Bandera street, E-mail: taras.i.chervinskyi@lpnu.ua

The process of pyrolysis of half-dimensional waste is carried out and the composition and properties of the obtained products are analyzed

Keywords - pyrolysis, pyrocondensate, pyrocarbon, polyethylene wastes, used tyres, recycling.

\section{Introduction}

Polymer wastes accumulated in huge quantities in landfills, scattered in forests and fields, floated on almost all water surfaces of our planet, significantly pollute the environment. Taking into account that wastes do not decompose, their quantity increases daily. This problem has already become a global one. In order to save the planet from catastrophic pollution by polymer waste, they must be utilized in a proper way. Known methods include incineration, recycling with reuse, and so on. The purpose of the work is to study the composition and properties of pyrocondensate pyrolysis of different types of polymer waste for their further use in the processes of obtaining commercial motor fuels.

\section{Results}

The basic properties of polyethylene pyrolysis pyrocondensate were studied. It was found that pyrocondensate and its narrow fractions do not contain sulfur but a significant amount of unsaturated (iodine number is $85.9 \mathrm{~g} \mathrm{I}_{2} / 100 \mathrm{~g}$ ) and paraffinic hydrocarbons, due to which they are characterized by unsatisfactory low-temperature properties (freezing point is $+4{ }^{\circ} \mathrm{C}$ ).

The basic properties of used tyres pyrolysis pyrocondensate and its narrow fractions were studied. A significant amount of unsaturated hydrocarbons (iodine number is $67.8 \mathrm{~g} \mathrm{I} / 100 \mathrm{~g}$ ) and sulfur (1.59 wt $\%)$ were found in them.

It was established that both pyrocondensate and narrow fractions cannot be used as marketable products. It was proposed to use those narrow fractions as raw materials for the production of commercial gasoline and diesel fuels together with the corresponding fractions at refineries.

The main properties of pyrocarbon obtained in the process of used tyres pyrolysis were studied. It was proposed to be used as an adsorbent for the collection and localization of oil and petroleum products spills on solid and water surfaces. The specific consumption of pyrocarbon is 1.02-1.46 g/g depending on the type of absorbed petroleum product.

The basics of the technology of polymer waste pyrolysis process were developed, in particular the basic technological scheme and process chart; the process material balance was calculated.

The main technical and economic indices of the pyrolysis installation for polymer wastes were calculated based on the example of used tyres pyrolysis. It is determined that the cost of pyrocondensate is $1565.55 \mathrm{UAH}$ per ton, and the payback period of the installation is 3 years.

\section{Conclusion}

The main properties of pyrocondensate of pyrolysis of polyethylene and worn car tires are studied. It is established that pyrocondensate and narrow fractions isolated from it can be used to obtain marketable motor fuels. It is established that pyrocarbon obtained in the process of pyrolysis of worn car tires can be used as an adsorbent for the absorption of petroleum products. 